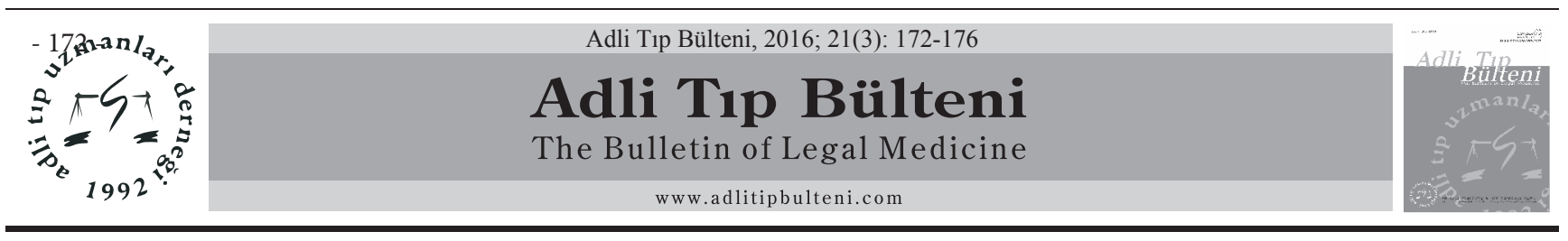

ARAŞTIRMA / RESEARCH ARTICLE

doi: $10.17986 / \mathrm{blm} .2016323751$

\title{
Üniversite Öğrencilerinde Risk Alma Davranışları ve Etkileyen Faktörlerin İncelenmesi
}

\author{
Risk Taking Behavior Amoung College Students and Factors Affecting this Behavior
}

Sunay Fırat', Elçin Yoldaşcan², Duygu Ayabakan Çot ${ }^{2}$, Nebile Dağlıoğlu ${ }^{3}$, Mete Korkut Gülmen ${ }^{3}$

${ }^{I}$ Çukurova Üniversitesi, Sağllk Bilimleri Fakültesi, Psikiyatri Hemşireliği ABD, Adana

${ }^{2}$ Çukurova Üniversitesi, Tip Fakültesi, Halk Sağlığı ABD, Adana

${ }^{3}$ Çukurova Üniversitesi, Tip Fakültesi, Adli Tip ABD, Adana

\begin{abstract}
Özet
Amaç: Sağlık açısından riskli davranışlar genellikle adolesan dönemde edinilmekte, sonuçları erişkin döneme yansıyarak, bu dönemde mortalite ve morbidite oranlarında önemli artışlara neden olmaktadır.

$\mathrm{Bu}$ araştırmada, üniversiteye devam eden gençlerin sigara, alkol ve bağımlılık yapıcı madde kullanımı, cinsel yaşam, kişisel güvenlik ve şiddete ilişkin bazı riskli davranışlarının saptanması amaçlanmıştır.

Gereç ve Yöntem: Bu araştırma, Çukurova Üniversitesi, merkez yerleşkesinde Kasım-Aralık 2015 tarihinde yürütülmüş tanımlayıcı tipte bir araştırmadır. Yazılı onamları alınan üniversite öğrencilerine demografik verileri sorgulayan soruların bulunduğu "Bilgi Formu" ve "Riskli Davranışlar Ölçeği-Üniversite Formu” uygulanmıştır. Riskli davranışlar ölçeği 60 maddelik likert tipi bir ölçektir. Antisosyal davranışlar, alkol kullanımı, sigara kullanımı, madde kullanımı, beslenme alışkanlıkları, intihar eğilimi, okul terki olmak üzere 7 bölümden oluşmaktadır. Bölümlerden alının puan artıkça risk artmaktadır. Veriler SPSS 20 paket programında değerlendirilmiştir.

Bulgular: Çalışmaya katılan 184 öğrencinin 105'i (\%57) kadın, 79'u (\%42,9) erkek öğrencidir. Öğrencilerin yaş ortalaması 20,21 1 1,91 (min:18, max: 39)'tır. Araştırmamızda üniversite eğitimi alan erkeklerin antisosyal davranışlar, sigara kullanımı, madde kullanımı, okul terki bölümlerinden aldıkları puanlar üniversite eğitimi alan kadınlardan daha yüksek bulunmuştur ve bu farklılık da istatistiksel olarak anlamlıdır $(p \leq 0,05)$. Çalışmamızda alkol kullanımı arkadaşlarıyla birlikte kalanlarda, aile yanı ve devlet yurdunda kalanlara göre daha yüksek bulunmuştur, sigara kullanımı ise arkadaşları ile birlikte kalanlarda, aileleri ile birlikte kalanlardan daha yüksek bulunmuştur $(\mathrm{p} \leq 0,05)$.

Sonuç: Çalışmamızda cinsiyet ve kişilerin yaşadıkları yer riskli davranışlarını etkileyen önemli belirleyicilerdendir. Gelenekleri de kapsayan farklı gerekçelerden kaynaklanan aile yanında beraber yaşama durumunun olduğu ülkemizde ailelerinden ayrılan gençler birbirlerinden etkilenmektedir. Gençleri hep beraber bulunduğu üniversite ortamlarında riskli davranışlardan korumaya yönelik etkinliklere ağırlık verilmeli, riskli davranışlardan korunmaları için gerekli yaşam becerilerini kazanmaları sağlanmalıdır.

Sonuç olarak gençlerin geleceğe yönelik olarak riskli davranışlarının anlaşılması ve önlenmesine yönelik üniversitelerde danışma birimleri kurulmalı, bu birimlerde uzmanlar tarafından eğitim toplantıları, grup oturumları düzenlenmeli ve gençler doğru yönlendirilmelidir.
\end{abstract}

Anahtar Kelimeler: Riskli davranışlar; Genç; Üniversite.

\begin{abstract}
Objective: Risky health behaviors are usually acquired during adolescence, but their effects are reflected in adulthood, causing significant increases in mortality and morbidity rates.

This study aims to examine risky behaviors among college students concerning the use of tobacco, alcohol and addictive substances, sexuality, personal safety, and violence.

Materials and Methods: This is a descriptive study conducted in the main campus of Çukurova University in November and December 2015. After receiving written approval, an "Information Form" designed to collect demographic data and the "Risky Behaviors Scale - College Form" were administered to college students. The risky behaviors scale is a 60-item Likert-type scale. It consists of seven sections: antisocial behavior, use of alcohol, use of tobacco, substance use, nutritional habits, suicidal tendency, and dropping out of school. Higher scores for each of these sections indicate higher risk. The data were analyzed using the software package SPSS 20.
\end{abstract}

Results: Of the 184 students participating in the study, 105 (57\%) were female and $79(42,9 \%)$ were male. The average age of the participants was 20,21 $\pm 1,91$ (min:18, $\max : 39$ ). Male students having university education had higher scores for antisocial behavior, use of tobacco, substance use, and dropping out of school, compared to female students having university education, and these differences were statistically significant $(p \leq 0,05)$. Students living with housemates had higher scores alcohol use compared to students living with their families or in dormitories, and for tobacco use compared to students living with their families $(\mathrm{p} \leq 0,05)$.

Conclusion: This study found that gender and living arrangements are significant determinants of risky behavior. In Turkey, living with one's parents is common, due to various reasons including customs, and young people living away from their parents are influenced by one another. More activities should be undertaken to protect young people from risky behaviors in college environments, which they share with many other students, and to help them acquire the necessary life skills to avoid risky behaviors.

In conclusion, counseling units should be established in colleges to understand and prevent risky behaviors among young people in the future, and training sessions and group sessions should be conducted by experts in these units to provide proper guidance to students.

Keywords: Risky Behaviors; Youth; University.
Sorumlu Yazar: Yrd. Doç. Dr. Sunay FIRAT

Çukurova Üniversitesi, Sağlık Bilimleri Fakültesi,

Psikiyatri Hemşireliği ABD, Adana

E-mail: sunayfirat@gmail.com

Geliş: 23.06.2016 Düzeltme: 01.09.2016 Kabul: 17.11.2016

\section{Giriş}

Ergenlikten erişkinliğe geçişin yaşandığı 18-25 yaşları arası yetişkinliğe geçiş olarak ifade edilmektedir (1). $\mathrm{Bu}$ döneme ilişkin yaşanan güçlüklerin temeli ergenlik 
dönemine bağlanabilir. Kişisel, sosyal veya gelişimsel olarak istenmeyen sonuçlara neden olan ve bireyin yaşamını birçok alanda tehlikeye atan davranışlar olarak tanımlanan $(2,3)$ riskli davranışlar bireyin içinde bulunduğu gelişim dönemini sağlıklı bir şekilde geçirmesini engellemesinin yanı sıra sonraki dönemlerde de yaşamında önemli sorunlara neden olabilmektedir.

Riskli davranışlar, genellikle ergenlik döneminde edinilmektedir. (4-6). Sağlık açısından riskli davranışlar, üniversite öğrencilerinde genel olarak sağlığı tehdit eden ve hayati tehlike yaratan (7), hastalık, yaralanma ve ölümle sonuçlanma olasılığı yüksek, sorumlu birer yetişkin olma hallerini engelleyen (8-12) davranışlar olarak tanımlanmaktadır.Bu tür davranışlar şiddet, madde kullanımı, intihar eğilimi, okul terki, korunmasız cinsel ilişki, olumsuz beslenme alışkanlıkları vb. biçiminde ortaya çıkabilmekte ve gençler için ciddi zarar verici ve hatta ölüme götüren sonuçlar doğurabilmektedir. Birçok riskli ortamın içinde bulunan gençlerin bu tür davranışlarında her geçen gün artış olduğu gözlemlenmektedir (12). Akran etkisinin en etkin olarak görüldüğü dönem ergenlik dönemi olarak ifade edilmektedir (13). Bu süreçte de gençler kimlerle daha fazla vakit geçiriyorsa bulunduğu grubun davranışlarından etkilenmektedir. Ergenlik döneminde akran etkisi çok önemli bir rol oynar. Ergenin alkol ya da diğer maddelere başlayıp başlayamayacağını öngörmede ergenin içinde bulunduğu akran gruplarının değerleri yol göstericidir (14). Gençlerin davranışlarını şekillendirmede en önemli faktörlerden biri de aile ile birlikte geçirilen zamandır. Aile üyeleri arasındaki güçlü iletişim ve birlikte vakit geçirme ile ergenin davranışları arasında pozitif bir ilişki vardır (15). Dahası, aktif ebeveyn ilişkisinin ve takibinin, ailenin rol model olmasının, madde kullanımında akran etkisini de azalttığı görülmüştür (16).

Gençler boş vakitlerini daha çok, arkadaşları ile denetlenmeyen aktivitelerde geçirdikleri ve bu durumun da madde kullanım riskini artırdığı araştırmalar kapsamında gözlenmiştir (17).

Ergenlikte yaşanan problemlerin kaynağı çoğunlukla bu dönemdeki biyolojik ve kimyasal değişimler olmakla birlikte, genç yetişkinlik döneminde yaşanan güçlüklerin asıl kaynağı sosyal ve kişisel değişimlerdir. Bu dönemde özellikle gençlerin mesleki ve sosyal gelişimleri buna bağlı olarak da kimlik gelişimleri önem kazanmaktadır. $\mathrm{Bu}$ gelişimsel görevlerin başarılmasında yaşanan gerilim de genç yetişkinlerin yaşamında bir stres kaynağ1 oluşt.u.rabilmekte ve onların riskli davranışlara yönelmesine neden olabilmektedir. Önemli risk alanlarının başında bilinçli olarak başkalarına ve eşyalara zarar verme olarak tanımlanan anti sosyal davranışlar gel- mektedir. (3) Bunu ise sigara, alkol ve madde kullanımı izlemektedir. Bunun yanı sıra sağlıksız beslenme alışkanlıkları bir risk alanı olarak gençlerin sağlıklarını ve yaşamlarını olumsuz yönde etkileyebilmektedir. Ayrıca bireyde var olan intihar riskini ifade eden (18) intihar eğilimi de önemli bir risk alanı olarak dikkat çekmektedir. Bununla birlikte üniversite öğrencileri için önemli bir risk alanının da bir öğrencinin mezun olmadan ya da devam ettiği programı tamamlamadan okuldan ayrılması olarak tanımlanan (19) okul terki olduğu düşünülmektedir.

Riskli davranışların belirlenmesi, birtakım önlemlerin alınmasının yanı sıra bu davranışlara neden olan değişkenlerin belirlenmesinde ve önleme programlarının geliştirilmesinde büyük önem taşımaktadır.

$\mathrm{Bu}$ araştırmada, üniversiteye devam eden gençlerin sigara, alkol ve bağımlılık yapıcı madde kullanımı, cinsel yaşam, kişisel güvenlik ve şiddete ilişkin bazı riskli davranışlarının sosyo demografik özellikler (yaş, cinsiyet, kaldıkları yer vb.) açısından değerlendirilmesi amaçlanmıştır.

\section{Gereç ve Yöntem}

$\mathrm{Bu}$ araştırma, Çukurova Üniversitesi, merkez yerleşkesinde Kasım-Aralık 2015 tarihleri arasında yürütülmüş tanımlayıcı tipte bir çalışmadır. Yazılı onamları alınan üniversite öğrencilerine demografik verileri sorgulayan soruların bulunduğu "Bilgi Formu" ve "Riskli Davranışlar Ölçeği-Üniversite Formu” (6,20)uygulanmıştır. Riskli davranışlar ölçeği 60 maddelik likert tipi ve antisosyal davranışlar, alkol kullanımı, sigara kullanımı, madde kullanımı, beslenme alışkanlıkları, intihar eğilimi, okul terki olmak üzere 7 alt bölümden oluşan bir ölçektir. Bölümlerden alının puan artıkça risk artmaktadır. Araştırma verilerinin analizleri SPSS 20,0 paket programında değerlendirilmiştir.

\section{Bulgular}

Çalışmaya katılan 184 öğrencinin 105'i (\%57) kı, 79'u $(\% 42,9)$ erkek öğrencidir (Grafik 1.). Öğrencilerin yaş ortalaması 20.21 $\pm 1,91$ (min:18, max: 39)'tır.

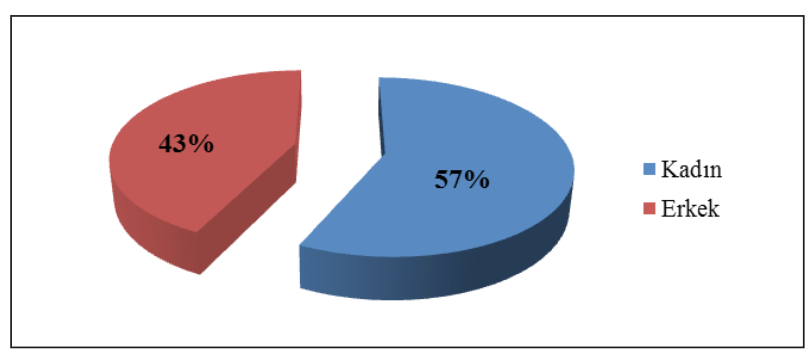

Grafik 1. Cinsiyet (\%). 


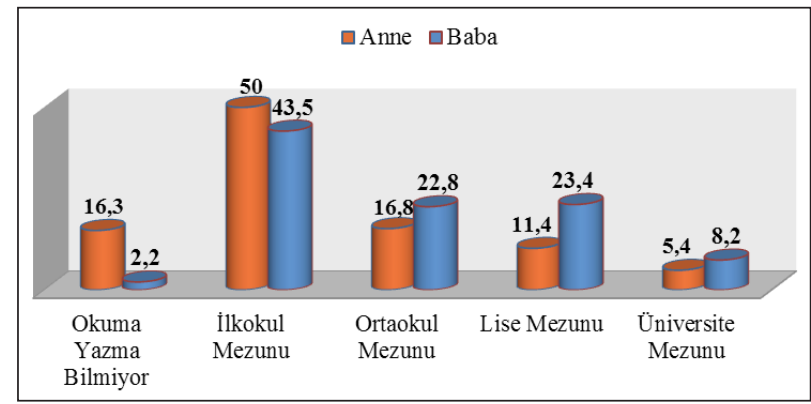

Grafik 2. Üniversite öğrencilerinin eğitim düzeyi (\%).

Grafik 2'ye göre, üniversite öğrencilerinin annelerinin $\% 50$ 'si, babalarının ise $\% 43,5$ 'i ilkokul mezunudur.

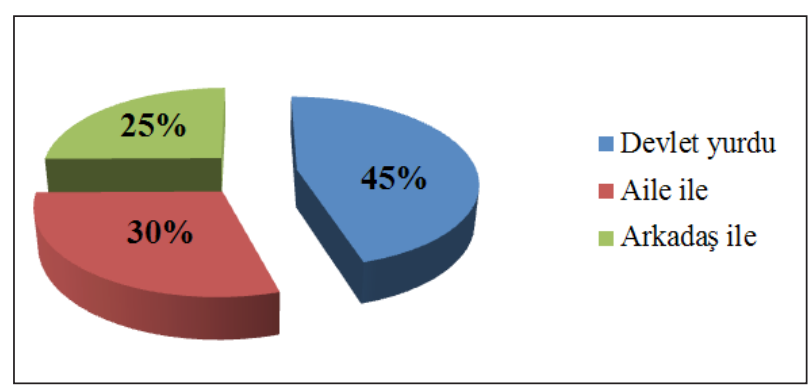

Grafik 3. Üniversite öğrencilerinin yaşadıkları yerler (\%).

Grafik 3'e göre, üniversite öğrencilerinin \%45'i devlet yurdunda, $\% 30$ 'u ailesi ile birlikte ve $\% 25$ 'si ise arkadaşları ile birlikte yaşadıklarını bildirmişlerdir.

Tablo 1. Risk alma davranışlarının cinsiyete göre karşılaştırılması.

\begin{tabular}{|l|l|c|c|}
\hline \multicolumn{1}{|c|}{$\begin{array}{c}\text { RiSK ALMA } \\
\text { DAVRANIŞLAR }\end{array}$} & CINSSIYET & Ort \pm sd & P \\
\hline Antisosyal & & & \\
Davranışlar & Kadın & $15,9 \pm 3,8$ & $<\mathbf{0 , 0 0 1}$ \\
\cline { 2 - 3 } & Erkek & $20,2 \pm 7,4$ & \\
\hline \multirow{2}{*}{ Alkol Kullanımı } & Kadın & $11,1 \pm 5,2$ & 0,55 \\
\cline { 2 - 3 } & Erkek & $13,0 \pm 7,8$ & \\
\hline \multirow{2}{*}{ Sigara Kullanımı } & Kadın & $11,2 \pm 5,7$ & $<\mathbf{0 , 0 0 1}$ \\
\cline { 2 - 3 } & Erkek & $16,0 \pm 8,7$ & \\
\hline \multirow{2}{*}{ İntihar Eğilimi } & Kadın & $22,0 \pm 8,7$ & 0,767 \\
\cline { 2 - 3 } & Erkek & $21,6 \pm 8,1$ & \\
\hline \multirow{2}{*}{$\begin{array}{l}\text { Beslenme } \\
\text { Alışkanlıkları }\end{array}$} & Kadın & $20,6 \pm 5,7$ & 0,456 \\
\cline { 2 - 3 } & Erkek & $21,3 \pm 6,8$ & \\
\hline \multirow{2}{*}{ Okul Terki } & Kadın & $7,1 \pm 2,5$ & $<\mathbf{0 , 0 0 1}$ \\
\cline { 2 - 3 } & Erkek & $8,7 \pm 3,5$ & \\
\hline \multirow{2}{*}{ Madde Kullanımı 1} & Kadın & $9,4 \pm 1,2$ & $<\mathbf{0 , 0 0 1}$ \\
\cline { 2 - 3 } & Erkek & $11,8 \pm 6,0$ & \\
\hline
\end{tabular}
$\mathrm{p}<0,05$
Tablo 1'e göre, erkek öğrencilerin risk alma davranışları değerlendirildiğinde, antisosyal davranışlar, sigara kullanımı, madde kullanımı, okul terki bölümlerinden aldıkları puanlar kız öğrencilerden daha yüksek bulunmuştur ve bu oran istatistiksel olarak anlamlıdır $(\mathrm{p}<0,05)$.

Tablo 2. Risk alma davranışlarının ortalamalara göre karşılaştırılması.

\begin{tabular}{|c|c|c|c|}
\hline $\begin{array}{l}\text { RISK ALMA } \\
\text { DAVRANIŞLAR }\end{array}$ & $\begin{array}{l}\text { KALDIKLARI } \\
\text { YERLER }\end{array}$ & Ort \pm sd & $\mathbf{P}$ \\
\hline \multirow{3}{*}{ Alkol Kullanımı } & Aile ile & $11,5 \pm 6,3$ & \\
\hline & Arkadaş ile & $15,4 \pm 9,1$ & $<\mathbf{0 , 0 0 1}$ \\
\hline & Devlet yurdu & $10,1 \pm 3,3$ & \\
\hline \multirow{3}{*}{ Sigara Kullanımı } & Aile ile & $12,2 \pm 5,2$ & \\
\hline & Arkadaş ile & $17,7 \pm 10,5$ & $<\mathbf{0 , 0 0 1}$ \\
\hline & Devlet yurdu & $11,5 \pm 5,6$ & \\
\hline $\mathrm{p}<0,05$ & & & \\
\hline
\end{tabular}

Tablo 2'e göre, üniversite öğrencilerinde alkol kullanımı arkadaşlarıyla birlikte kalanlarda aile yanı ve devlet yurdunda kalanlara göre daha yüksek bulunmuştur $(\mathrm{p}<0,05)$, sigara kullanımı ise arkadaşları ile birlikte kalanlarda, aileleri ile birlikte kalanlardan istatistiksel olarak daha yüksek bulunmuştur ( $\mathrm{p}<0,05)$.

\section{Tartışma ve Sonuç}

Çalı̧̧mamızda üniversiteye devam eden gençlerin sigara, alkol ve bağımlılık yapıcı madde kullanımı, cinsel yaşam, kişisel güvenlik ve şiddete ilişkin bazı riskli davranışlarının belirlenmesi amaçlanmış, bulgular literatür 1̧̧ı̆̆ında tartışılmış ve yorumlanmıştır.

Araştırmamızda cinsiyet ve gençlerin yaşadıkları yer, risk alma davranışlarını etkileyen önemli belirleyicilerdendir (21-23).Gelenekleri de kapsayan farklı gerekçelerden kaynaklanan aile yanında beraber yaşama durumunun olduğu ülkemizde ailelerinden ayrılan gençler birbirlerinden etkilenmektedir.

Çalışmamızda erkeklerin kızlara göre daha fazla risk alma davranışları sergiledikleri belirlenmiştir (24-27). Erkek öğrencilerin risk alma davranışları değerlendirildiğinde, antisosyal davranışlar, sigara kullanımı, madde kullanımı, okul terki bölümlerinden aldıkları puanlar kız öğrencilerden daha yüksek bulunmuştur ve bu oran istatistiksel olarak anlamlıdır $(\mathrm{p}<0,05)$. Geleneksel toplumsal 
cinsiyet rollerinin yaygın olduğu toplumlarda kadınlar yaşam alanlarıyla ilgili daha az girişimlerde (eylemlerde) bulunmaktadırlar. Buna karşın erkekler daha bağımsız ve özgür davranmalarının desteklenmesiyle yaşam alanlarıyla ilgili daha fazla girişimlerde bulunmaktadırlar. Bu girișimler sırasında erkekler daha fazla riskli davranıșlar gösterebilmektedirler. Ülkemizde de benzer şekilde geleneksel toplumsal cinsiyet rolleri (erkeklerin/kadınların doğuştan getirdikleri ve sosyal davranışlarda cinsiyet farklılıkları birleştirmekte ve böylece cinsiyete özgü toplumsal roller oluşmaktadır) benzer olarak daha yaygın görülmektedir (28).

Sigara ve alkol kullanımı, gençlerde sık rastlanan risk alma davranışlarındandır (29). Öğrencilerin yaşadıkları yer, riskli davranışlarını etkilemektedir. Çalışmamızda, sigara ve alkol kullanımı, arkadaşları ile evde kalanların devlet yurdu ve aileleri ile birlikte kalanlara göre daha fazla riskli davranışlarda bulunduğu saptanmıştır. Yapılan bir araştırmaya göre, evde arkadaşları ile yaşayanların ve yurtta kalanların, ailesi ile birlikte yaşayanlara göre, daha fazla riskli davranışlarda bulunduğu saptanmıştır. Aile yanında beraber yaşama geleneğinin yaygın olduğu ülkemizde, ailelerinden ayrılan gençler birbirlerinden etkilenmekte ve birlikte bulundukları üniversite ortamında riskli davranışlar içeren etkinliklere yönelmektedirler. $\mathrm{Bu}$ durum arkadaş etkisini göstermektedir (11).

Sosyal desteğin, bireyin çevresinden gördüğü ilgi, sevgi, güven, sayg1, takdir edilme, bilgi edinme ve maddi yardım gibi kişisel, sosyal, psikolojik ve ekonomik nitelikli her türlü yardım olarak tanımlandığı (30) dikkate alındığında bireyin yaşamındaki olumlu etkileri daha iyi anlaşılabilmektedir. Zaman zaman gençler, gereksinimlerini karşılamak ya da problemlerine çözüm bulmak amacıyla riskli davranışlara yönelebilmektedirler.

Çalışmamızın sonuçları değerlendirildiğinde; Barnes ve Farrell (1992), ebeveyn desteğinin gençlerde alkol kullanımı, suça yönelik davranışlar ve diğer problem davranışların önemli bir yordayıcısı olduğunu belirtmişlerdir (31). Piko (2000) ise babadan algılanan sosyal desteğin gençlerde sigara, alkol ve madde kullanımını önemli ölçüde etkilediğini bildirmişlerdir (32). Rosenfeld, Richman ve Bowen, (2000) ve Simantov, Schoen, Klein (2000), sosyal desteğin ergenleri riskli davranışlara karşı koruyucu bir etkisi olduğunu bildirmişlerdir $(33,34)$. Lagana'ya (2004) göre ise yetişkin ve arkadaş desteği almayan gençlerde okul terki riskinin daha fazla olduğu bildirilmiştir (35). Bu çalışmaların sonuçları aile, arkadaş ve öğretmen desteğinin, gençlerde antisosyal davranışlar, madde kullanımı, okul terki gibi riskli davranışların önemli yordayıcıları olduğunu göstermektedir. Bu bağlamda araştırma sonucunda elde edilen bu bulgu- lar bu alanda yapılan çalışmaların sonuçları ile paralellik göstermektedir. Aile yapısı, sosyal, kültürel ve ekonomik durum gibi değişkenlerin çalışmaya katılmaması çalışmamızın önemli bir sınırlılığıdır.

Bu çalışmada riskli davranışlar antisosyal davranışlar, alkol kullanımı, sigara kullanımı, intihar eğilimi, beslenme alışkanlıkları ve okul terki boyutlarını içeren toplam bir değişken olarak ele alınmıştır. Gelecekte tek tek bu alt boyutları yordayan değişkenlerin belirlenmesine yönelik olarak yeni araştırmalar yapılabilir.

Sonuç olarak, sosyal desteğin üniversiteye devam eden gençleri riskli davranışlara karşı koruyucu bir etkisi olduğu bildirilmiştir (33). Bu nedenle gençleri üniversite ortamlarında riskli davranışlardan korumaya yönelik psiko-eğitimsel programlar geliştirilmeli, riskli davranışlardan korunmaları için gerekli yaşam becerilerini kazandırılmaya çalışılmalıdır. Özellikle erkeklerin risk almaya daha eğilimli oldukları ve bu nedenle önleme programlar1 hazırlanırken toplumsal cinsiyet örüntülerinin de göz önünde bulundurulması yararlı olacaktır.

\section{Kaynaklar}

1. Steinberg L. Ergenlik, Ankara: İmge Kitabevi Yayınları, 2007.

2. Santrock JW. Yaşam boyu gelişim (Çeviren: Galip Yüksel (ed.). 3. Bask1, Ankara: Nobel Yayınları, 2011.

3. Jessor R, Turbin MS. Parsing protection and risk for problem behavior versus pro-social behavior among US and Chinese adolescents. Journal of youth and adolescence, 2014;43(7):1037-1051. DOI 10.1007/s10964-014-0130-y.

4. Grunbaum JA, Kann L, Kinchen SA, Ross J, Hawkins J, Lowry R, et al. Youth Risk Behavior Surveillance United States, 2003, CDC MMWR Surveillance Summaries 2004;53(2):1-96.

5. Ottawa Charter for Health Promotion. WHO/HPR/ HEP/95.1. WHO, Geneva, 1986.

6. Gençtarım Kuru D. Ergenlerde riskli davranıșların yordanmas1. Hacettepe Üniversitesi Sosyal Bilimler Enstitüsü Eğitim Bilimleri Anabilim Dalı, Psikolojik Danışma ve Rehberlik Bilim Dalı, Doktora Tezi. 2010, Ankara.

7. Cleary SD. Adolescent victimization and associated suicidal and violent behaviors. Adolesence 2000;35(140):671-693.

8. Grunbaum JA, Kann L, Kinchen SA, Williams B, Ross J, Lowry R, Kolbe L, et al. Youth Risk Behavior Surveillance United States, 2001, MMWR Surveillance Summaries 2002;51(4):1-62.

9. Refaal A. Practice and awareness of health risk behaviour among Egyptian university students. EMHJ 2004;10(1-2):72-81.

10. CDC. Adolescent\&School Health,YRBSS, 2003 High School Survey, Item Rationale, http.//www.cdc.gov/nccdphp/ dash/yrbs/2003/rationale.htm, Erişim Tarihi: 05.06.2016.

11. Çamur D, Üner S, Çilingiroğlu N, ve Özcebe H. Bir üniversitenin bazı fakülte ve yüksek okullarında okuyan gençlerde bazı risk alma davranışları. Toplum Hekimliği Bülteni, 2007;26(3):32-38. 
12. Lindberg LD, Boggess S, Porter L, Williams S. Teen RiskTaking: A Statistical Portrait.2000. http://files.eric.ed.gov/ fulltext/ED441924.pdf Erişim: 1 Nisan 2016.

13. Dalkılıç A, Yılmaz H, Unlu A, Evcin U, Prajapati P. ve Pumariega AJ. Risk factors for suicidal 1deation among high school students in Istanbul. Adolescent Psychiatry 2013;3(1):102-113.

14. Bayraktar F. Olumlu ergen gelişiminde ebeveyn/akran ilişkilerinin önemi. Çocuk ve Gençlik Ruh Sağlığı Dergisi, 2007;14(3):157-166.

15. Ferguson KM. Social capital and children's wellbeing: a critical synthesis of the international social capital literature. International Journal of Social Welfare, 2006;15(1):218. DOI: $10.1111 /$ j.1468-2397.2006.00575.x.

16. Abar C, Turrisi R. How important are parents during the college years? A longitudinal perspective of indirect influences parents yield on their college teens' alcohol use. Addictive Behaviors, 2008;33:1360-1368. doi:10.1016/j.addbeh.2008.06.010.

17. Gilman R, Meyers J, Perez L. Structured extracurricular activities among adolescents: findings and implications for school psychologists. Psychol in the Schools, 2004;41(1):31-40. DOI: 10.1002/pits. 10136.

18. Gençtanırım D. Ergenlerde intihar olasılığının yordanması. Yayınlanmamış Yüksek Lisans Tezi. Hacettepe Üniversitesi: Sosyal Bilimler Enstitüsü, Ankara, 2004.

19. McWhirter JJ. McWhirter RJ, Candidate JD. Preventing adolescent suicide, 2013.

20. Gençtanırım D. Riskli Davranışlar Ölçeği Üniversite Formu: Geçerlik ve Güvenirlik Çalışmaları Journal of Measurement and Evaluation in Education and Psychology 2014;5(1): 24-34.

21. Lee A, Tsang CKK. Youth risk behavior in a Chinese population: a territory-wide youth risk behavioural surveillance in Hong Kong. Public Health 2004;118:88-95. http://dx.doi. org/10.1016/S0033-3506(03)00174-4

22. Avery L, Lazdane G. What do we know about sexual and reproductive health of adolescents in Europe? Eur J Contracept Reprod Health Care. 2007;1-13. http://dx.doi. org/10.1080/13625180701617621

23. Johansen A, Rasmussen S, Madsen M. Health behavior among adolescents in Denmark: Influence of school class and individual risk factors. Scand J Public Health. 2006;34:32-40. DOI: 10.1080/14034940510032158.

24. Arnett JJ, Balle-Jensen. Cultural bases of risk behavior: Danish adolescent, Child Development 1993;64:18421855. DOI: $10.2307 / 1131473$.

25. Byrness JP, Miller DP. Gender differences in risk taking: A meta analysis, Psychological Bulletin, 1999;125:367-383.

26. Morsünbül Ü. Attachment and risk taking: Are they interrelated? International Journal of Human and Social Sciences 2009;4:234-238.

27. Yurtsever Z. Üniversite Gençlerinde Riskli Davranışlar. Yayımlanmamış Yüksek Lisans Tezi, Erciyes Üniversitesi, Sosyal Bilimler Enstitüsü, 2011.

28. Özmen O, Sümer ZH. Predictors of risk-taking behaviors among Turkish adolescents. Personality and Individual Differences 2011;50:4-9. doi:10.1016/j.paid.2010.07.015.

29. Tanrıkulu AÇ, Çarman KB, Palancı Y, Çetin D, Karaca M. Kars il merkezinde çeşitli Üniversite öğrencileri arasında sigara kullanım sıklığı ve risk faktörleri. Tur Toraks Der 2009;11:101-106.

30. Yıldırım, İ. Anne baba desteği ve başarı. Ankara: Anı Yayınc1lik, 2006.

31. Barnes GM. and Farrell MP. Parental support and control as predictors of founda adolescent drinking, delinquency, and related problem behaviors. Journal of Marriage and the Family, 1992;54:763-776. DOI: 10.2307/353159.

32. Piko B. Perceived social support from parents and pers: which is the stronger predictor of adolescent substance use? Substance use \&Misuse, 2000;35(4):617-630. http://dx.doi. org $/ 10.3109 / 10826080009147475$

33. Rosenfeld LB, Richman JM, Bowen GL. Social support networks and school outcomes: The centrality of the teacher. Child and Adolescent Social Work Journal 2000;17(3):205-226.

34. Simantov E, Schoen C and Klein JD. Health-compromising behaviors: why do adolescents smoke or drink? indentify underlying risk and protective factors. Pediatrics and adolescent medicine, 2000;154(10):1025-1033. doi:10.1001/ archpedi.154.10.1025.

35. Lagana MT. Protective factors for inner-city adolescents at risk of school dropout: family factors and social supoort. Children \& Schools, 2004;26(4):211-220. 